\title{
Adaptation of the Heart to Hypertension is Associated with Maladaptive Gap Junction Connexin-43 Remodeling
}

\author{
M. FIALOVÁ ${ }^{1}$, K. DLUGOŠOVÁ ${ }^{1}$, L. OKRUHLICOVÁ ${ }^{1}$, F. KRISTEK ${ }^{2}$, M. MANOACH ${ }^{3}$, \\ N. TRIBULOVÁ ${ }^{1}$ \\ ${ }^{1}$ Institute for Heart Research and ${ }^{2}$ Institute of Normal and Pathological Physiology, Slovak \\ Academy of Sciences, Bratislava, Slovak Republic, ${ }^{3}$ Department of Physiology, Tel Aviv \\ University, Tel Aviv, Israel
}

Received August 30, 2006

Accepted November 15, 2006

On-line available January 2, 2007

\begin{abstract}
Summary
We hypothesized that hypertension-related myocardial remodeling characterized by hypertrophy and fibrosis might be accompanied by cell-to-cell gap junction alterations that may account for increased arrhythmogenesis. Intercellular junctions and expression of gap junction protein connexin-43 were analyzed in rat heart tissues from both spontaneous (SHR) and L-NAME model of hypertension. Isolated heart preparation was used to examine susceptibility of the heart to lethal ventricular fibrillation induced by low potassium perfusion. Ultrastructure observation revealed enhanced neoformation of side-to-side type while internalization of end-to-end type (intercalated disc-related) of gap junctions prevailed in the myocardium of rats suffering from either spontaneous or L-NAME-induced hypertension. In parallel, immunolabeling showed increased number of connexin43 positive gap junctions in lateral cell membrane surfaces, particularly in SHR. Besides, focal loss of immunopositive signal was observed more frequently in hearts of rats treated with L-NAME. There was a significantly higher incidence of hypokalemia-induced ventricular fibrillation in hypertensive compared to normotensive rat hearts. We conclude that adaptation of the heart to hypertension-induced mechanical overload results in maladaptive gap junction remodeling that consequently promotes development of fatal arrhythmias.
\end{abstract}

\section{Key words}

Gap junction remodeling • Connexin-43 • Hypertension • Malignant arrhythmias

\section{Corresponding author}

N. Tribulova, Institute for Heart Research, Slovak Academy of Sciences, Bratislava, Slovak Republic.

E-mail: Narcisa.Tribulova@savba.sk

\section{Introduction}

Alteration of structure (remodeling) is a fundamental response of the heart to injury or disease. A change in cardiac structure inevitably leads to a change in cardiac function, but the complex relationship between altered structure and function are not fully understood. Although structural remodeling serves important adaptive purposes, maladaptive consequences of remodeling are likely to contribute to morbidity and mortality in patients with heart disease due to myocardial infarction or systemic hypertension (He and Whelton 1999). Development of cardiomyocyte hypertrophy allows the heart to function better in condition of chronic hypertension. However, structural alterations can also change patterns of electrical activation of the heart that may enhance the risk of malignant arrhythmias, such as ventricular tachycardia and fibrillation. Indeed, conduction slowing and unidirectional conduction block, necessary for initiation and maintenance of re-entrant circuit, often arise in viable, but structurally altered myocardium (Gardner 1985, Peters et al. 1997). We hypothesize that structural alterations may not involve only cardiomyocyte and extracellular matrix changes but also intercellular junction alterations.

There are three types of intercellular junctions, preferentially located at the intercalated disc, which ensure synchronized electromechanical function of the heart. Adhesive junctions, such as desmosome and fascia adherens, are responsible for cell-to-cell adhesion and cell-to-cell contractile force transduction, intermyocyte electrical coupling and metabolic signal transduction are

PHYSIOLOGICAL RESEARCH • ISSN 0862-8408 (print) • ISSN 1802-9973 (online)

(c) 2008 Institute of Physiology v.v.i., Academy of Sciences of the Czech Republic, Prague, Czech Republic

Fax +420 241062 164, e-mail: physres@biomed.cas.cz, www.biomed.cas.cz/physiolres 
Table 1. Geometry of the thoracic aorta (W - normotensive Wistar rats, W-H - hypertensive rat due to L-NAME treatment, SHR spontaneously hypertensive rats)

\begin{tabular}{lccc}
\hline & W & W-H & SHR \\
\hline Wall thickness $(\mu \mathrm{m})$ & $63.16 \pm 2.37$ & $81.87 \pm 1.69^{*}$ & $81.08 \pm 2.27^{*}$ \\
Cross-sectional area $\left(\mu \mathrm{m}^{2}\right) \times 10^{3}$ & $343 \pm 11.6$ & $483 \pm 9.78^{*}$ & $452 \pm 18.35^{*}$ \\
Inner diameter $(\mu \mathrm{m})$ & $1690 \pm 44.37$ & $1792 \pm 32.78$ & $1688 \pm 36.81$ \\
Wall thickness/inner diameter $x 10^{-2}$ & $3.78 \pm 0.19$ & $4.55 \pm 0.13^{*}$ & $4.81 \pm 0.17^{*}$ \\
\hline
\end{tabular}

* $\mathrm{P}<0.01$ hypertensive $v s$. normotensive Wistar rats

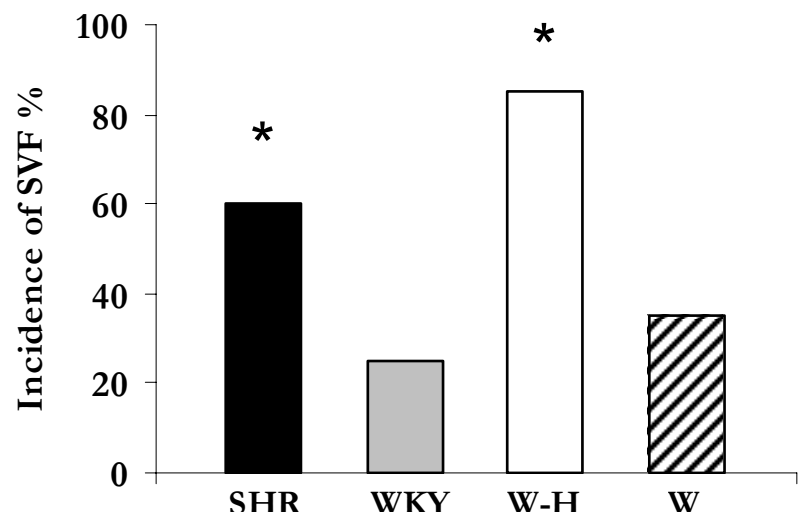

Fig. 1. Incidence of sustained ventricular fibrillation (SVF) that was induced by perfusion of the heart with low $\mathrm{K}^{+}$solution for 15 min, unless SVF occurred earlier. SHR - spontaneously hypertensive rats $(n=8) ; \mathrm{W}-\mathrm{H}$ - hypertensive rats due to L-NAME treatment $(n=6) ;$ WKY - Wistar-Kyoto rats $(n=8)$ and W - Wistar $(\mathrm{n}=6)$ age-matched non-hypertensive controls. $* \mathrm{P}<0.05$, hypertensive $v s$. nonhypertensive.

ensured via gap junctions. These specialized membrane regions contain numerous connexin protein channels, which directly connect the cytoplasmic compartments of two adjacent cells.

The goal of our study was to investigate alterations of myocardial gap junctions, as well as susceptibility of the heart to sustained ventricular fibrillation (VF) using two different rat models of experimental hypertension.

\section{Methods}

The investigation conformed to the NIH Guide for the Care and Use of Laboratory Animals. Experiments were performed on male rats that were either spontaneously hypertensive (SHR) or hypertension was induced in 12-week-old Wistar rats by treatment with L-NAME (40 mg/kg for 4 weeks, see Pecháňová et al. 1999). Males were used becase they are more sensitive to heart failure and they express less connexin-43 compared to females (Soukup et al. 2001, Tribulová et al. 2005). Heart and aorta tissues were excised from 16-week-old hypertensive and age-matched non-hypertensive rats. Blood pressure was measured using tail-cuff method. Perfusion technique with glutaraldehyde was performed to fix thoracic aorta followed by procedure to obtain slices suitable for quantitative image analysis, as previously described (Kristek and Gerová 1996). Glutaraldehyde-fixed ventricular heart tissue samples were routinely processed for transmission electron microscopy. Myocardial cryostat sections were used for in situ immunodetection of major gap junction protein, connexin-43 using mouse monoclonal antiCx43 antibody and FITC conjugated goat anti-mouse antibody (details in Tribulová at al. 1999). The hearts from each group (SHR and WKY n=16, L-NAME and Wistar $n=12$ ) were perfused in Langendorff mode with oxygenated KrebsHenseleit solution (KHS) at constant pressure and temperature followed by $15 \mathrm{~min}$ perfusion (unless VF occurred earlier) with $\mathrm{K}^{+}$-deficient Krebs-Henseleit solution to induce sustained VF (details in Tribulová et al. 2001). Statistical significance between groups was determined by Student's t-test or Fisher's exact test for comparison of the incidence of ventricular fibrillation. The data were expressed as means \pm S.E.M. and the differences were considered as significant when $p<0.05$.

\section{Results}

Compared to non-hypertensive rats, there was a significant increase of blood pressure in SHR and L-NAME-treated animals: $206 \pm 5$ and $180 \pm 4$ vs. controls $138 \pm 10$ (WKY) and $127 \pm 2 \quad \mathrm{~mm} \mathrm{Hg}$ (Wistar). Hypertension induced cardiac hypertrophy as indicated by increase of heart to body weight ratio from $3.12 \pm 0.04$ and $2.68 \pm 0.03$ to $4.32 \pm 0.33$ and $3.06 \pm 0.16$, as well as by apparent thoracic aorta remodeling (Table 1). The latter was documented by significant increase of arterial 

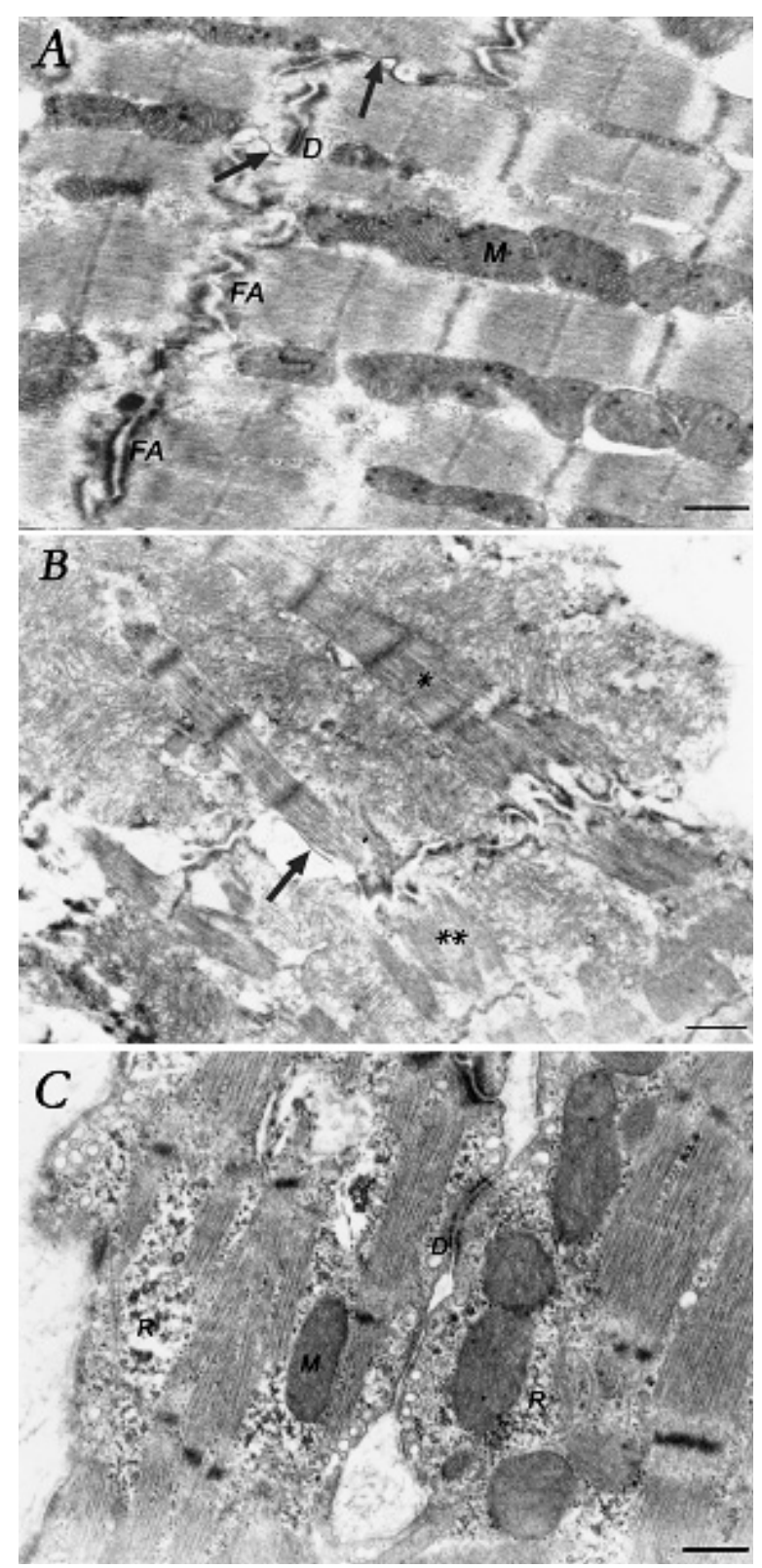

Fig. 2. Representative pictures showing heterogeneous population of cardiomyocytes in the myocardium of hypertensive rats. A. Ultrastructure of cardiomyocytes and their junctions are not apparently altered. Note electron dense mitochondria, relaxed sarcomeres and maintained integrity of intercalated discrelated intercellular junctions. B. Injured cardiomyocytes show electron lucent mitochondria, contracted $\left(^{*}\right)$ or relaxed $(* *)$ sarcomeres and impaired integrity of intercellular junctions, fascia adherens and gap junction. C. Hypertrophied cardiomyocytes exhibiting abundant polyribosomes and creating adhesive junctions at the cell-to cell contacts that precedes gap junction formation. Arrows - gap junctions, R - polyribosomes, M mitochondria, FA - fascia adherens junctions, D - desmosomes (adhesive junctions). Bar scale $1 \mu \mathrm{m}$.

wall thickness in both hypertensive models compared to normotensive rats.

Development of VF due to perfusion of the heart with low $\mathrm{K}^{+}$solution preceded ventricular premature beats and transient arrhythmias that occurred earlier in
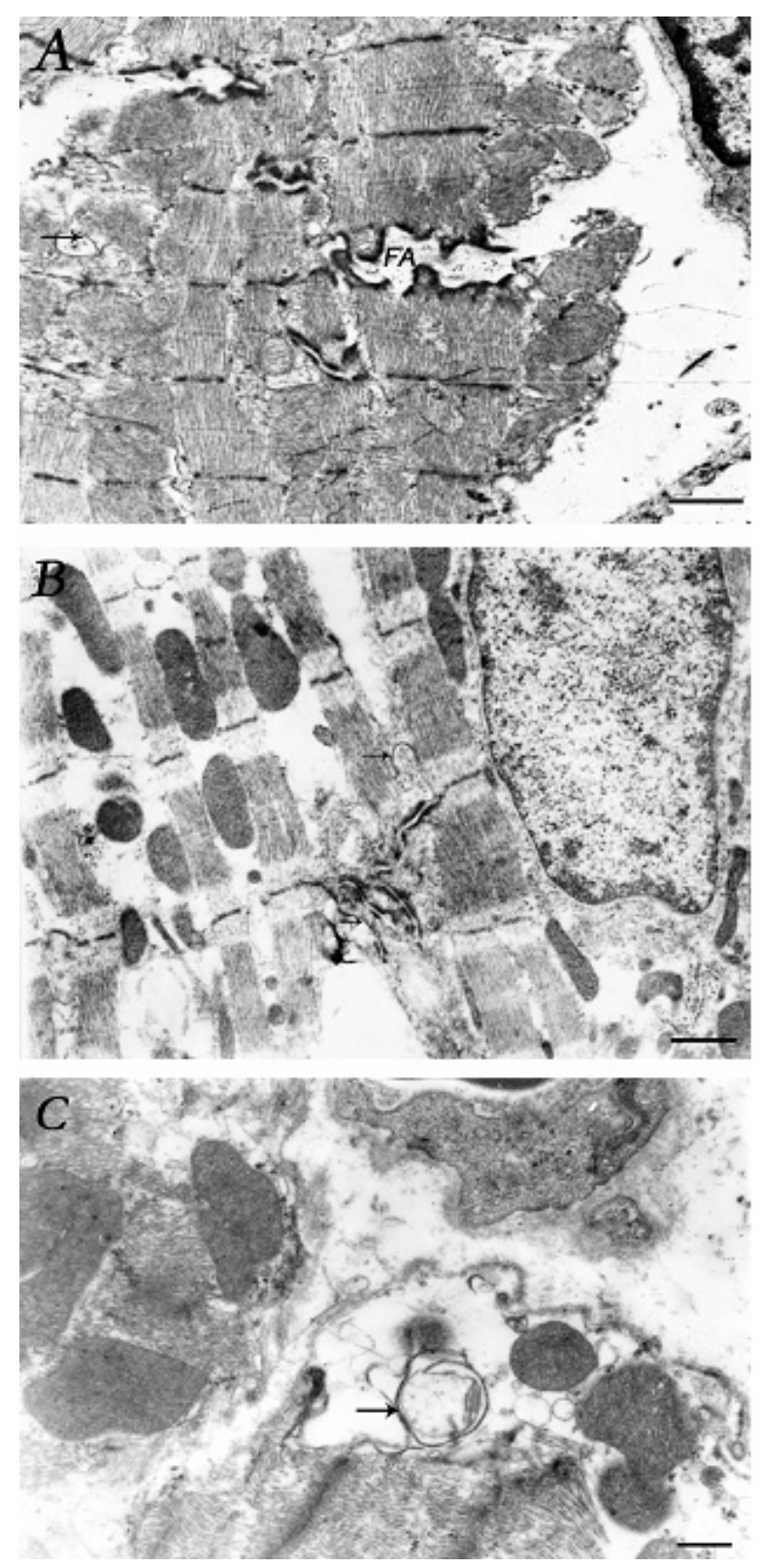

Fig. 3. Typical subcellular alterations of intercellular junctions found in the hypertensive rat heart. A. Dehiscence (separation) of fascia adherens junctions (FA) and internalization of gap junction (arrow). B. Neoformation of lateral, side-to-side type of gap junctions between adjacent hypertrophied cardiomyocytes (arrows). C. Internalization of gap junctions and presence of annular profile (arrow), it precedes their degradation. Bar scale $1 \mu \mathrm{m}$.

hypertensive rat hearts (not shown). Irrespective of the etiology, hypertensive rat hearts were significantly more vulnerable to develop sustained $\mathrm{VF}$, during $15 \mathrm{~min}$ of low $\mathrm{K}^{+}$perfusion, compared to non-hypertensive rats (Fig. 1). Accordingly, sustained VF occurred in five of eight SHR hearts and in five of six L-NAME-treated rat hearts, while only in two WKY or Wistar rat hearts.

Electron microscopic examination revealed heterogeneous population of cardiomyocytes in the left 
ventricles of both groups of hypertensive rats. Characteristic changes are documented in Figure 2 (L-NAME model). Besides normal cells (Fig. 2A), numerous cardiomyocytes are hypertrophied, possessing active nuclei, enhanced rough sarcoplasmic reticulum, increased number of mitochondria, new myofilaments and formation of a lateral adhesive junctions (Fig. 2B). The latter was followed by neoformation of side-to-side type of gap junctions (Fig. 3B). On the other hand, some hypertrophied cardiomyocytes exhibited degenerative subcellular changes consisting of electron lucent edematous mitochondria, focal myocytolysis and nonuniform sarcomere shortening (Fig. 2C). In addition, enhanced accumulation of collagen and fibrosis were observed in L-NAME model only (not shown).

Hypertension-induced subcellular changes were accompanied with cell-to-cell junction alterations, which were heterogeneously distributed throughout myocardium. As shown in Figure 3 (SHR model) alterations were characterized by dehiscence (separation) of fascia adherens junctions (Fig. 3A), by neoformation of side-to-side gap junctions (Fig. 3B) and by internalization of end-to-end (intercalated disc-related) type of gap junctions (Fig. 3C).

In parallel with these changes immunolabeling of connexin-43 revealed two features of alterations that were present in both models of hypertensive rats. There was an enhanced connexin-43 expression confined to lateral side-to-side type of gap junctions (Fig. 4B) and focally diminished or lost intercalated disc-related connexin-43 expression (Fig. 4C). The former feature was more pronounced in SHR while the latter in L-NAME-treated rat hearts.

\section{Discussion}

Many observations suggest that the myocardial architecture as well as the number, size and spatial distribution of gap junctions play an important role in determining the conduction properties of cardiac tissues (Spach and Heidlage 1995). Reduction in the total amount of gap junction profile length as well as gap junction protein expression in diseased ventricular myocardium have been implicated in the pathogenesis of slow conduction and unidirectional conduction block leading to malignant re-entrant arrhythmias (Peters et al. 1997, Saffitz et al. 1999, Severs 2001).

In agreement with this, the results of this study likewise our previous studies suggest that chronic or acute impairment of intercellular coupling at the gap junctions precedes the occurrence of malignant arrhythmias (Tribulová et al. 2001, 2002).

Changes in gap junction distribution (remodeling of gap junctions) usually results from chronic pathophysiological stimuli (e.g., hypertension, diabetes, ischemia), whereas acute pathophysiological conditions (e.g. hypokalemia, ischemia/reperfusion) induce temporary alterations of gap junctions indicated by a marked reduction or the loss of connexin-43 immunopositivity (Tribulová et al. 2002). While lateralization of gap junctions decreases myocardial electrical stability probably due to changes in anisotropic conduction (Spach and Heidlage 1995), the acute impairment of electrical coupling can trigger malignant arrhythmia due to re-entrant (re-excitation) mechanism.

It should be noted that hearts exhibiting gap junction remodeling are more vulnerable to lethal arrhythmias because they are also prone to develop a $\mathrm{Ca}^{2+}$ overload (during acute ischemia or electrolyte dysbalance) since they have abnormal $\mathrm{Ca}^{2+}$ handling. A $\mathrm{Ca}^{2+}$ overload can lead to both spontaneous $\mathrm{Ca}^{2+}$ oscillations that can trigger early or delayed afterdepolarization and connexin channels inhibition that can induce cell-to-cell uncoupling (de Mello 1986). Indeed, $\mathrm{Ca}^{2+}$ overload and cell-to-cell uncoupling were detected previously in hypertensive rat hearts subjected to low potassium perfusion (Tribulová et al. 2001, 2002). $\mathrm{Ca}^{2+}$ overload was indicated when cardiomyocytes exhibited contraction bands or nonuniform sarcomere shortening and cell-to-cell uncoupling when relaxed cardiomyocyte was "connected" by gap junctions with contracted one (Fig. 2C) or when severely injured cardiomyocyte was "connected" with slightly injured or even intact one.

In conclusion, there is no doubt that abnormalities of gap junctions may be involved in the development of malignant arrhythmias. As gap junctions are highly dynamic structures, they are promising target aimed to prevent or attenuate the incidence of lethal events in patients with diseased hearts.

\section{Conflict of Interest}

There is no conflict of interest.

\section{Acknowledgements}

This study was supported by VEGA 2/6064/26, 2/5021/26 and APVV 51-059505 grants. 


\section{References}

DE MELLO WC: Interaction of cAMP and $\mathrm{Ca}^{2+}$ in the control of electrical coupling in the heart fibers. Biochim Biophys Acta 888: 91-99, 1986.

GARDNER PI, URSELL PC, FENOGLIO JJ, WIT AL: Electrophysiologic and anatomic basis for fractionated electrograms recorded from healed myocardial infarcts. Circulation 72: 596-611, 1985.

HE J, WHELTON PK: Elevated systolic blood pressure and a risk of cardiovascular and renal disease. Am Heart J 138: 211-219, 1999.

KRISTEK F, GEROVÁ M: Long-term NO synthase inhibition affects heart weight and geometry of coronary and carotid arteries. Physiol Res 45: 361-367, 1996.

PECHÁŇOVÁ O, BERNÁTOVÁ I, PELOUCH V, BABÁL P: L-NAME-induced protein remodeling and fibrosis in the rat heart. Physiol Res 48: 353-362, 1999.

PETERS NS, COROMILAS J, SEVERS NJ, VIT AL: Disturbed connexin43 gap junction distribution correlates with the location of reentrant circuits in the epicardial zone of healing canine infarcts that cause ventricular tachycardia. Circulation 95: 988-996, 1997.

SAFFITZ JE, SCHUESSLER RB, YAMADA KA: Mechanisms of remodelling of gap junction distribution and the development of anatomic substrates of arrhythmias. Cardiovas Res 42: 309-317, 1999.

SEVERS NJ: Gap junction remodelling and cardiac arhythmogenesis: cause or coincidence? J Cell Mol Med 5: $355-$ $366,2001$.

SOUKUP T, ZACHAŘOVÁ G, SMERDU V, JIRMANOVÁ L: Body, heart, thyroid gland and skeletal muscle weight changes in rats with altered thyroid status. Physiol Res 50: 619-626, 2001.

SPACH MS, HEIDLAGE JF: The stochastic nature of cardiac propagation at a microscopic level. An electrical description of myocardial architecture and its application to conduction. Circ Res 76: 366-380, 1995.

TRIBULOVÁ N, VARON D, POLAK-CHARCON S, BUSCEMI P, SLEZÁK J, MANOACH M: Aged heart as a model for prolonged atrial fibrilloflutter. Exp Clin Cardiol 4: 64-72, 1999.

TRIBULOVÁ N, MANOACH M, VARON D, OKRUHLICOVÁ L, ZINMAN T, SHAINBERG A: Dispersion of cellto-cell uncoupling precedes low $\mathrm{K}^{+}$-induced ventricular fibrillation. Physiol Res 50: 247-259, 2001.

TRIBUlOVÁ N, OKRUHLICOVÁ L, NOVÁKOVÁ S, PANCZA D, BERNÁTOVÁ I, PECHÁŇOVÁ O, WEISMANN P, MANOACH M, SEKI S, MOCHIZUKI S: Hypertension-related intermyocyte junction remodelling is associated with a higher incidence of low- $\mathrm{K}^{+}$-induced lethal arrhythmias in isolated rat heart. Exp Physiol 87: 195-205, 2002.

TRIBULOVÁ N, DUPONT E, SOUKUP T, OKRUHLICOVÁ L, SEVERS NJ: Sex differences in connexin-43 expression in left ventricles of aging rats. Physiol Res 54: 705-708, 2005. 